Para citar este artículo: Arroyo, I., López, A. y Gutiérrez, A. (2017). Solidarydar.org: un experimento de cooperación en comunicación social digital entre la universidad y el tercer sector de acción social. Anuario Electrónico de Estudios en Comunicación Social “Disertaciones”, 10(1), 42-65. Doi: dx.doi.org/10.12804/ revistas.urosario.edu.co/disertaciones/a.4532

\title{
SOLIDARYDAR.ORG: UN EXPERIMENTO DE COOPERACIÓN EN COMUNICACIÓN SOCIAL DIGITAL ENTRE LA UNIVERSIDAD Y EL TERCER SECTOR DE ACCIÓN SOCIAL
}

\section{Solidarydar.org: an Experiment of Cooperation in Digital Communication between the University and the Third Sector of Social Action}

Solidarydar.org: Um experimento de cooperação em Comunicação social digital entre a Universidade e o Terceiro Setor de Ação Social

\author{
Arroyo-Almaraz, Isidoro. Universidad Rey Juan Carlos (Madrid) \\ isidoro.arroyo@urjc.es
}

López, Alejandro. Gestor del proyecto Solidarydar.org

Alejandrolopezdiaz87@gmail.com

Gutiérrez, Andrea. Gestora de contenidos digitales de la agencia McCann. andrea.gubi8@gmail.com

Fecha de recibido: 31 de enero de 2016

Fecha de aceptado: 23 de marzo de 2016 


\title{
DISERTACIONES
}

ENSAYOS

Anuario electrónico de estudios en Comunicación Social

ISSN: 1856-9536

Doi: dx.doi.org/10.12804/revistas.urosario.edu.co/disertaciones/a.4532

Volumen 10, Número 1/ Enero-junio 2017

Versión PDF para imprimir desde

http://revistas.urosario.edu.co/index.php/disertaciones

\section{RESUMEN}

La solidaridad necesita un esfuerzo especial por conseguir eficacia en su comunicación estratégica. En el marco de investigación de la Comunicación y las Ciencias Sociales, esta cuestión es un objeto de estudio. Sin embargo, para el Tercer Sector de Acción Social (TSAS), surge la duda de si están funcionando correctamente las herramientas de la web 2.0 y 3.0. Para responder a esta pregunta, se fundó en 2007 Solidarydar.org, un proyecto experimental de aprendizaje y servicio con la misión de dinamizar la comunicación digital de las causas sociales por medio de la creatividad publicitaria y la investigación en comunicación social digital. Es un espacio de encuentro entre las organizaciones del TSAS y los alumnos de Publicidad. El trabajo cuenta con una dinámica de colaboración de la Universidad con el TSAS para la realización de comunicación social digital. Se ha construido un soporte web multicanal consistente en una página web y en perfiles en diversas redes sociales; estas han ofrecido un buen rendimiento de audiencias en la comunicación de las campañas de comunicación de las ocho ediciones del Festival Universitario Solidarydar.org y las Jornadas de publicidad social. Se han hecho más de 150 campañas publicitarias para más de cincuenta organizaciones.

Palabras clave: tercer sector de acción social, cooperación, creatividad publicitaria, aprendizaje y servicio, Web 2.0 y 3.0 .

\begin{abstract}
Solidarity needs a special effort to achieve efficiency in their strategic communications. From the research framework of Communication and Social Sciences, this issue is a subject of study. However, since the Third Sector of Social Action (TSAS) doubts whether the tools are running web 2.0 and 3.0 correctly arises. To answer this question, an experimental service learning project with a mission to stimulate the digital communication of social causes through advertising creativity and research in digital social communication it is founded in 2007 Solidarydar.org. It is a meeting space for organizations and students TSAS Advertising. The work is done under a dynamic collaboration of the University with the TSAS for performing digital social communication. It has built a multi-channel web support consisting of a website and profiles on different social networks that have offered good performance of audiences in communicating the different communication campaigns through eight editions of the University Festival Solidarydar.org and social advertising Seminar. There have been over 150 advertising campaigns for more than 50 organizations.
\end{abstract}

Keywords: third sector of social action, cooperation, advertising creativity, service-learning, web 2.0 and 3.0 .

\section{RESUMO}

A solidariedade precisa um esforço especial para conseguir eficácia na sua comunicação estratégica. Desde o marco investigador da Comunicação e as Ciências Sociais, esta questão é um objeto de estudo. No entanto, desde o Terceiro Setor de Ação Social (TSAS) surge a dúvida de se estão funcionando corretamente as ferramentas da web 2.0 e 3.0. Para responder a esta pergunta funda-se em 2007 Solidarydar, um projeto experimental de apren- 


\section{DISERTACIONES}

ENSAYOS

Anuario electrónico de estudios en Comunicación Social

ISSN: 1856-9536

Doi: dx.doi.org/10.12804/revistas.urosario.edu.co/disertaciones/a.4532

Volumen 10, Número 1 / Enero-junio 2017

Versión PDF para imprimir desde

http://revistas.urosario.edu.co/index.php/disertaciones

dizagem e serviço com a missão de dinamizar a comunicação digital das causas sociais, através da Criatividade publicitária e a Investigação em Comunicação social digital. É um espaço de encontro entre as organizações do TSAS e os alunos e Publicidade. 0 trabalho se realiza sob uma dinâmica de colaboração da Universidade com o TSAS para a realização de Comunicação social digital. Se tem construído um suporte web multicanal consistente em um site e em perfiles em diferentes redes sociais que têm oferecido um bom rendimento de audiências na comunicação das diferentes campanhas de comunicação através das oito edições do Festival Universitário Solidarydar e as Jornadas de Publicidade social. Se têm realizado mais de 150 campanhas publicitárias para mais de 50 organizações.

Palavras-chave: Terceiro setor de ação social, Cooperação, Criatividade publicitária, Aprendizagem e serviço, Web 2.0. e 3.0

\section{Introducción}

\section{Estado de la cuestión}

La realidad financiera y comunicativa actual del tercer sector en España, así como los cambios producidos por el desarrollo de las nuevas tecnologías, en particular de las redes sociales, la web 2.0 y la 3.0 favorecen una comunicación social con potencial revolucionario y emancipador.

La búsqueda permanente de captación de fondos por parte de las organizaciones del tercer sector, como consecuencia de los recortes en los gastos sociales del Estado, ha obligado al $80 \%$ de las organizaciones a desarrollar nuevas estrategias de financiación, que han pasado de depender del Estado, como principal fuente de ingresos, a buscar una financiación propia o de las empresas.

El desarrollo de esas nuevas estrategias para la financiación se ha convertido en el reto mayoritario señalado por un $77,7 \%$ de las organizaciones, cuando se trata de la organización no gubernamental, y un 75,1\% cuando se trata del sector. Sin embargo, este reto afecta de forma desigual a las organizaciones según su tamaño. De manera que las pequeñas y medianas en términos de ingresos, empleo, o voluntariado, tienen menos posibilidades para la captación de recursos y, como consecuencia de ello, afrontan resultados económicos negativos (gastan más de lo que ingresan).

Otro reto para este segmento es el de una mayor profesionalización, y todo lo que ello implica en estándares de calidad, evaluación de la acción, marketing social, captación de recursos, transformación digital, etc. (Ramírez del Río, Delgado y Gómez, 2015).

Estos cambios estructurales modifican la forma de relacionarse de las organizaciones con sus públicos, lo que las impulsa a utilizar las nuevas tecnologías para redirigir su comunicación hacia los grandes públicos. Por otra parte, también se está generando una nueva comunicación que va dirigida a la creación y mantenimiento de 


\section{DISERTACIONES}

ENSAYOS

Anuario electrónico de estudios en Comunicación Social

ISSN: $1856-9536$

Doi: dx.doi.org/10.12804/revistas.urosario.edu.co/disertaciones/a.4532

Volumen 10, Número 1 / Enero-junio 2017

Versión PDF para imprimir desde

http://revistas.urosario.edu.co/index.php/disertaciones

vínculos permanentes entre las ONG y sus socios, voluntarios, colaboradores y públicos (Herranz de la Casa, 2009; Cerdá, 2003; Erro, 2002; Aranguren, 1998; Angulo, 1998 y Aguadero, 1993).

Los esfuerzos por sobrevivir de las pequeñas y medianas organizaciones pueden interferir con el papel de sensibilización social que llevan a cabo y desvirtuar el sentido de su comunicación (Grzybowski, 2001), con el consiguiente riesgo de dirigirlas en primer lugar, hacia la captación de fondos y, solo, en segundo lugar, a fomentar la movilización de la opinión pública a favor de aquellos colectivos más desfavorecidos por la crisis en favor de temas como la vivienda, la integración social o una mayor atención a la infancia. Además de dejar relegados otros asuntos más estratégicos, como los relacionados con las relaciones exteriores, la capacidad de adaptación a los cambios normativos y políticos, la consolidación del sector como agente interlocutor de la sociedad civil, las alianzas operativas entre entidades, la generación de un nuevo modelo de financiación, y la involucración de las empresas en la acción social (Ramírez del Río, Delgado y Gómez, 2015).

En este contexto social, comunicar de forma eficaz se convierte en un medio imprescindible para realizar actividades de carácter humanitario. Por esta razón, las ONG tendrán que innovar, forzosamente, en casi todos los aspectos relacionados con la organización, con la financiación y con la comunicación, para mejorar la percepción que el público y la sociedad tienen de ellas. Para ello, la innovación en la comunicación deberá centrarse en la dimensión creativa, contando, por ejemplo, historias que movilicen y conmuevan mediante el storytelling (Jenkins, 2003), y utilizando mayoritariamente los recursos de la sociedad digital con sus hipermediaciones (Scolari, 2008).

Por tanto, el ámbito de la innovación está supeditado, en buena medida, a su presencia en la red, ya probada con los movimientos sociales ligados a las tecnologías, como fue el caso del $15 \mathrm{M}^{1} \mathrm{y}$ las movilizaciones pos $15 \mathrm{M}$ que supieron saltar de la red a la calle, y de esta a los medios de comunicación convencionales (Ferreras, 2011). En la innovación es necesario aprovechar las posibilidades de interactividad de los medios digitales así como la convergencia mediática, crossmedia y transmedia, en favor del aumento de la cultura participativa que, según Marí (2007) es muy necesaria para la construcción colectiva del conocimiento, ya que como indica Jenkins, (2008):

El término "cultura participativa" contrasta con nociones más antiguas del espectador mediático pasivo.

Más que hablar de productores y consumidores mediáticos como si desempeñasen roles separados, podría-

mos verlos hoy como participantes que interaccionan conforme a un nuevo conjunto de reglas (p. 15).

Orihuela define en parte esas reglas al hablar de las dimensiones de las tres c: "comunicación, al permitir poner en común los conocimientos; comunidad, al ayudar a integrar comunidades; y cooperación, al ayudar a hacer cosas juntos" (Ramil, 2005, p. 1).

La primera c es la de la Comunicación, que se refiere a la idea de dar a conocer, de compartir, de poner en común proyectos, informaciones, conocimientos, etc. La segunda c que indica Orihuela es la de la Comunidad, es decir, el conjunto de personas vinculadas por características o intereses comunes. La tercera y última c es la de la Cooperación, que hace referencia a hacer cosas juntos con el objetivo de alcanzar un mismo fin. Estas conforman la esencia del tercer sector. Por esta razón, las redes sociales se erigen como plataforma de comunicación entre los que viven la cooperación en primera persona (cooperantes y voluntarios en los países beneficiarios) y la sociedad en general, como lo prueba el mayor uso en 2015, respecto de 2011, de las plataformas interactivas de los social media.

1 El Movimiento de los Indignados, denominado 15M por llevarse a cabo el 15 de mayo de 2011, día en que diversos colectivos convocaron manifestaciones pacíficas por toda España. 


\section{DISERTACIONES}

ENSAYOS

Anuario electrónico de estudios en Comunicación Social

ISSN: 1856-9536

Doi: dx.doi.org/10.12804/revistas.urosario.edu.co/disertaciones/a.4532

Volumen 10, Número 1 / Enero-junio 2017

Versión PDF para imprimir desde

http://revistas.urosario.edu.co/index.php/disertaciones

Gráfico 1. Estudio comparativo del uso de herramientas tecnológicas (2011-2015)

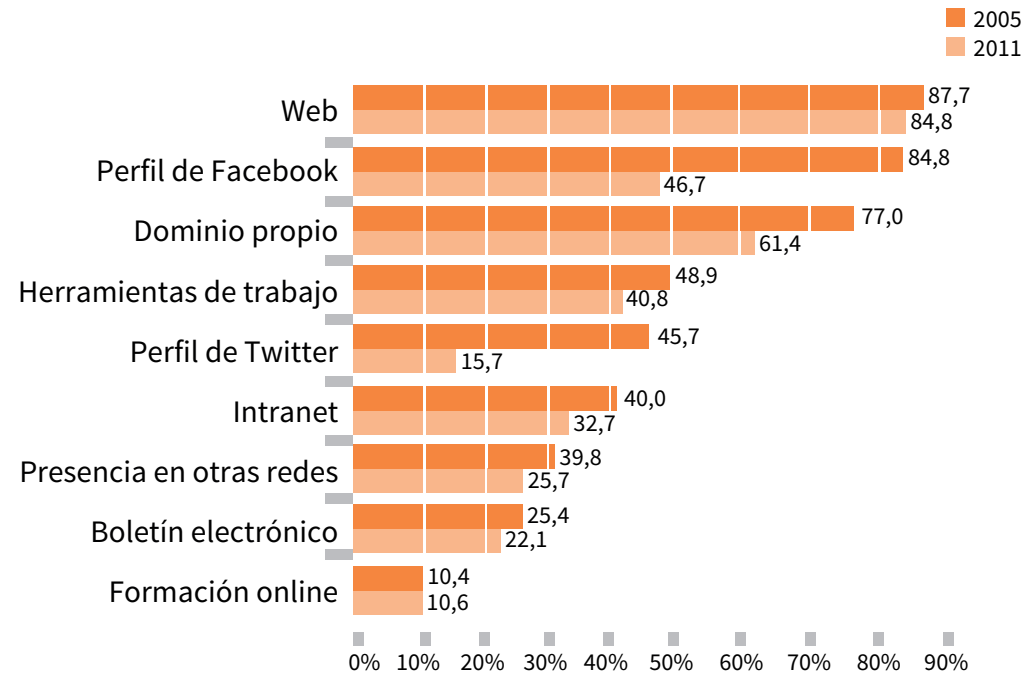

Fuente: Anuario del Tercer Sector de Acción Social (2015).

Tal y como se puede apreciar en el gráfico 1, el uso de herramientas on line: chat, foros, wikis, grupos de correo o videoconferencias es utilizado por el 48,9\% de las organizaciones, aumentando así en 8,1 puntos desde 2011. Por otra parte, las organizaciones han duplicado el uso de Facebook, pasando de un $46,7 \%$ a un $84,8 \%$, y triplicado el uso de Twitter pasando de un 15,2\% a un 45,2\%, en 2011.

Este éxito se debe a que Facebook es idóneo para interactuar con los voluntarios y donantes porque favorece conexiones permanentes con ellos y generan un amplio capital social. Twitter, por su parte, es el medio de comunicación más completo para las ONG por su capacidad de movilización, que gracias a sus mensajes breves le permite hacer llegar la información de forma masiva, a bajo coste y en tiempo real. Los blogs favorecen la inserción de videos y, junto con YouTube, facilitan la creación de canales de comunicación personalizados, gratuitos y abiertos al público en general. Además, los videos pueden generar un efecto de viralidad al usar las llamadas técnicas de Marketing WOM Digital o de Buzz Marketing.

El éxito se debe también a la utilización de técnicas como el Digital Signage. Se trata de un nuevo medio digital que se origina out, y que acaba convirtiéndose en un medio on, difundiéndose de forma masiva en las redes sociales como Instagram, YouTube, Facebook y Twitter; y genera impactos sobre millones de personas.

También es importante el conocimiento de los públicos y la valoración que hagan estos de las propias organizaciones. Es un paso previo y necesario para la consecución de notoriedad para las causas que defienden, así como para la obtención de credibilidad por su transparencia y fiabilidad. La confianza de los donantes, voluntarios y beneficiarios es básica para obtener el respaldo institucional o privado.

En general, las organizaciones del sector han mantenido en su conjunto una buena imagen; en 2015, dos tercios de las entidades del Tercer Sector de Acción Social (TSAS) (69,3\%) perciben que la sociedad tiene una buena imagen del sector y que tiene confianza en él. Concretamente, el 56,9\% cree que la sociedad confía bastante en 


\section{DISERTACIONES}

ENSAYOS

Anuario electrónico de estudios en Comunicación Social

ISSN: 1856-9536

Doi: dx.doi.org/10.12804/revistas.urosario.edu.co/disertaciones/a.4532

Volumen 10, Número 1/ Enero-junio 2017

Versión PDF para imprimir desde

http://revistas.urosario.edu.co/index.php/disertaciones

el sector, y el $12,4 \%$ que lo hace mucho. Sin embargo, cuando se trata de saber si una organización concreta es conocida lo suficiente en su ámbito de actuación, ese porcentaje ha ido descendiendo en 13,2\% respecto a los datos de 2011.

Por ello, cada día cobra mayor importancia el posicionamiento de cada ONG en buscadores y, por tanto, es necesario que tenga clara la imagen y los valores con los que quiere ser conocida y se diferencia del resto de las asociaciones del mismo tipo. Sus acciones y sus mensajes determinan su posicionamiento comunicativo, y logran un lugar en la mente del consumidor basado en los valores que transmite, en sus funciones sociales y, sobre todo, buscando la diferenciación con el resto de sus competidores. Buenos ejemplos de ello son Cáritas, que representa la lucha contra la pobreza; Cruz Roja, en su dimensión de protección social; Médicos sin Fronteras, como referente de ayuda sanitaria; Manos Unidas, vinculada a la defensa del Tercer Mundo; Greenpeace, un referente de la protección del medio ambiente, Amnistía Internacional, en la lucha por la defensa de los Derechos Humanos, etc.

Y, por último, la utilización de la publicidad en las Adwords de Google mediante Google Grants que ofrece la posibilidad de aparecer en un medio eficaz y rentable como es Internet, además de dar la oportunidad de introducirnos en el mayor buscador de la red, por lo tanto, es garantía de éxito. Gracias a esta aplicación se pueden acercar los mensajes y acciones a un público mucho más numeroso y diverso. Así, por ejemplo, Unicef ha utilizado el programa Google Grants, y ha aumentado la captación de fondos en cerca de un $43 \%$, con respecto al año anterior, así como la intención de colaboración de voluntarios.

\section{Planteamiento del estudio}

\section{Objetivo principal}

El principal objetivo de este trabajo es favorecer la cooperación de las entidades del tercer sector con otras entidades e instituciones. Se busca incrementar el nivel de cooperación y el trabajo en red entre las entidades del tercer sector y los estudiantes de Publicidad y Relaciones Públicas. Por medio de la realización de campañas de comunicación que permiten el contacto de las organizaciones con la sociedad civil y la captación de apoyos entre los estudiantes, a la vez que los estudiantes incrementan su responsabilidad con la participación en las organizaciones, y su autonomía en la toma de decisiones con sus colaboraciones y propuestas de comunicación. 


\section{DISERTACIONES}

ENSAYOS

Anuario electrónico de estudios en Comunicación Social

ISSN: 1856-9536

Doi: dx.doi.org/10.12804/revistas.urosario.edu.co/disertaciones/a.4532

Volumen 10, Número 1/ Enero-junio 2017

Versión PDF para imprimir desde

http://revistas.urosario.edu.co/index.php/disertaciones

Gráfico 2. Entidades del TSAS que cooperan con agentes sociales. Comparación 2011-2015

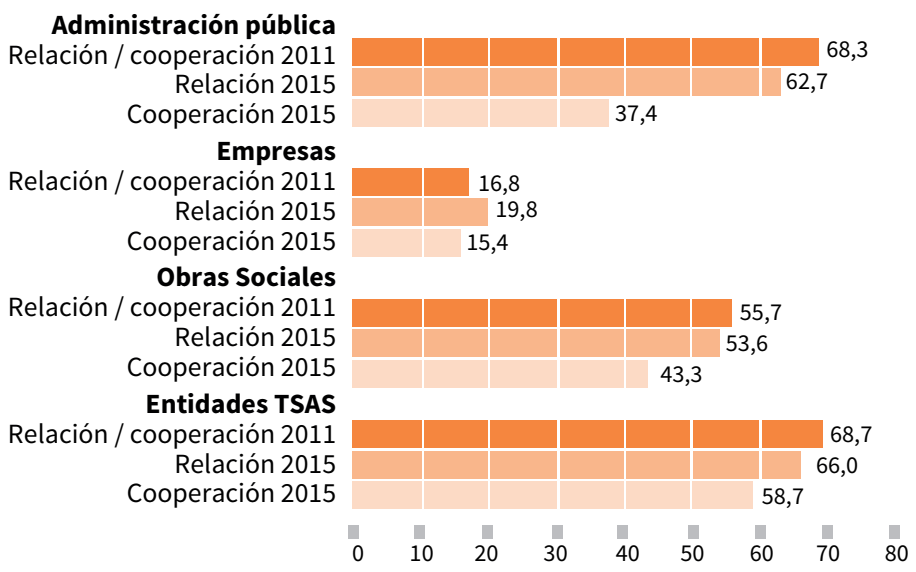

Fuente: Anuario del Tercer Sector de Acción Social (2015).

El Tercer Sector de Acción Social ha interactuado siempre con distintos agentes sociales con los que tradicionalmente ha establecido relaciones de cooperación.

En los datos del gráfico 2 se observa una relación frecuente con las administraciones, pero de ello no se puede deducir que esta se traduzca en una cooperación adecuada, como por ejemplo ocurre con la insuficiente cooperación con el mundo de la universidad, sobre todo en un momento como el actual caracterizado por una caída de la financiación pública.

Cabría esperar que debido a la crisis financiera ante la caída de ayudas y subvenciones, y junto con otras nuevas iniciativas de financiación como el crowdfunding, el consumo colaborativo, los grupos de consumo, el comercio justo, o, los bancos de tiempo se hubieran desarrollado iniciativas dirigidas a la comunicación exterior como la que proponemos en este trabajo, toda vez que como las propias organizaciones indican:

Mediante una buena estrategia de comunicación las entidades pueden aumentar la visibilidad de su organización y mejorar el posicionamiento [...] atraer de forma eficaz asociados y patrocinadores [...] obtienen un valor diferencial en su ámbito de actuación y les permite atraer financiación con menos dificultades (Ramírez del Río, Delgado y Gómez, 2015, p. 114).

En particular son las entidades de los niveles 2 y 3 , es decir, aquellas con presupuestos menores, en las que se observa una mayor intencionalidad de incrementar dicha colaboración. Y por ello se convierten en el objetivo preferente de proyectos como el que presentamos. Por tanto, el objetivo de esta investigación es tener un punto de unión y sinergia entre el tercer sector y los comunicadores arriba propuestos, lo cual nos sirve como punto de partida para reflexionar sobre las posibilidades de conectar a dos agentes que se necesitan para realizar una experiencia de trabajo colaborativo con una ONG, haciendo las veces de anunciante y permitiendo a los estudiantes enfrentarse a problemas reales de comunicación. Con esta cooperación los estudiantes desarrollan sus capacidades y habilidades profesionales, al mismo tiempo que aprenden y ayudan a las organizaciones. Los alumnos-comunicadores contribuyen al ofrecer sus capacidades profesionales y las entidades-anunciantes del tercer sector 


\section{DISERTACIONES}

ENSAYOS

Anuario electrónico de estudios en Comunicación Social

ISSN: $1856-9536$

Doi: dx.doi.org/10.12804/revistas.urosario.edu.co/disertaciones/a.4532

Volumen 10, Número 1 / Enero-junio 2017

Versión PDF para imprimir desde

http://revistas.urosario.edu.co/index.php/disertaciones

contribuyen al ofrecer la experiencia de trabajar para una ONGD, ONG o asociación desarrollando una campaña de comunicación publicitaria.

Este tipo de iniciativa se lleva desarrollando en la Universidad Rey Juan Carlos desde el 2003 por medio de una difusión Off, pero es solo desde 2015 cuando empieza una nueva etapa de difusión On, sirviéndose de las potencialidades comunicativas y operativas de las Tecnologías de la Información y la Comunicación (TIC). Con esta finalidad surge Solidarydar.org, una plataforma que actualmente tiene 5.703 visitas (dato consultado desde Google Analytics, en el periodo del 1 de enero de 2015 al 27 de junio de 2015).

Esta plataforma se creó con la finalidad de agrupar todos los proyectos desarrollados desde 2007 en Solidarydar.org y tener un punto de unión y sinergia entre el tercer sector y los comunicadores-alumnos. También tiene el propósito de mostrar diferentes investigaciones del sector y, noticias de actualidad, entre otros. Pero sobre todo lo que se quiere alcanzar es que esta plataforma sea un referente en el tercer sector, que ayude a difundir la publicidad social de las organizaciones y que involucre en este proceso a los alumnos y comunicadores interesados en obtener experiencia profesional para enfrentarse al mundo real de la comunicación.

Solidarydar.org tiene como objetivo principal conectar a dos agentes que se necesitan para realizar una comunicación eficiente del tercer sector, los alumnos-comunicadores y las entidades-anunciantes, mediante una cooperación basada en el desarrollo de una campaña de comunicación publicitaria en el medio digital. Esta propuesta se enmarca en el modelo teórico de aprendizaje-servicio (service-learning) (Arroyo, 2015) que introduce un cambio metodológico consistente, básicamente, en el desarrollo de una experiencia de solidaridad (service) ejercida por los estudiantes que buscan resolver un problema concreto de comunicación, y que forma parte de un programa de aprendizaje institucional reglado o formal (learning).

Los estudiantes desarrollan un conjunto de habilidades, destrezas, conocimientos y actitudes necesarias para el desempeño óptimo en una ocupación o función productiva determinada, que promueva el trabajo autónomo y la toma de decisiones de los alumnos, y a la vez, sirve de motivación e implicación de los estudiantes. Como señala Alonso (citado en Arroyo, 2015):

El desarrollo de sus capacidades cognitivas y emotivas permite que los estudiantes sean competentes y realicen de forma adecuada lo que se espera de ellos. Sin embargo, disponer de capacidades no es suficiente si no se establece un contacto con la vida real; es decir, conviene que los contenidos que se impartan, se complementen con un enfoque más cercano a la práctica profesional (p. 196).

Las organizaciones TSAS establecen su cooperación en forma de convenios de colaboración, de intercambio de información, de asesoramiento, de relaciones de tipo económico (subvenciones, donaciones, etc.), de prestación de servicios o de cesión de espacios. En el caso de nuestro proyecto, la cooperación con las organizaciones del tercer sector se establece con un convenio de colaboración entre la Universidad y las ONG que permite un proceso de trabajo similar al que realizan las agencias de publicidad al elaborar las campañas publicitarias. Pero, para que un convenio así tenga éxito, se debe conectar con una actividad formativa de aprendizaje-servicio. Ello obliga también a desarrollar en los estudiantes el pensamiento crítico, enfatizando la solidaridad como un valor en la metodología que se usa para desarrollar así competencias y habilidades profesionales acordes con el contexto (Arroyo, 2015, p. 196). 


\section{Objetivos específicos}

El primer objetivo específico ha sido el desarrollo de la plataforma web con el fin gestionar el proyecto educativo por medio de la nube y favorecer un rápido acceso de todos los agentes. Con esta aportación on line se ahorra tiempo y se obtiene inmediatez tanto para ofrecer proyecto por parte del tercer sector, como para aceptar las colaboraciones por parte de los comunicadores-alumnos.

Los otros objetivos particulares han sido:

- Crear un espacio de encuentro on line entre comunicadores-alumnos y el tercer sector para realizar proyectos con un fin social.

- Mostrar los proyectos realizados por los alumnos-comunicadores que ya se habían realizado y los que se están realizando.

- Complementar la plataforma con un repositorio y base de datos de investigaciones relacionadas con la publicidad social que fueran útiles tanto para los alumnos como para los responsables de las organizaciones del tercer sector.

- Convertir la plataforma en un sitio de referencia donde mostrar la actualidad en publicidad social y la creatividad de las causas sociales.

- Favorecer en los estudiantes de comunicación, la responsabilidad en su participación con las organizaciones sin ánimo de lucro y la autonomía en la toma de decisiones en sus colaboraciones y propuestas de comunicación.

- Generar una experiencia de trabajo colaborativo con una organización del tercer sector, que hace las veces de anunciante, y que permite a los estudiantes enfrentarse a problemas reales de comunicación. Con esta cooperación los estudiantes desarrollan sus capacidades y habilidades profesionales, al mismo tiempo que aprenden y ayudan a las organizaciones.

\section{Marco metodológico}

Retomamos el marco metodológico que ya presentamos con anterioridad (Arroyo, 2015) de esta actividad que se fundamenta, por una parte, en las perspectivas críticas de la teoría de la comunicación y que vincula a la sociedad civil con la universidad mediante estos cambios metodológicos. Y, por otra parte, "en la perspectiva tecnológica que establece que cualquier comunicación mejora cuando se utilizan Tecnologías de la Información y Comunicación porque aumenta la información sobre la realidad, la transmiten más rápidamente y mejora la captación de atención" (Arroyo, 2015, p. 195). Por esto, la herramienta con la que se lleva a cabo esta práctica educativa es una plataforma web, al ser una de las mejores herramientas y soportes para poder desarrollar estas acciones.

El proyecto favorece la autonomía del alumno y le traslada la responsabilidad del proyecto en un contexto de supervisión y control académico. Se trata de una primera experiencia intermedia entre el mundo académico y el mundo profesional. Por tanto, cada grupo de trabajo experimenta una vivencia distinta a la de los demás grupos, adaptándose a las peticiones particulares de la ONG, con un trasfondo común para todos los alumnos de investigación, determinación de estrategia y objetivos, generación de ideas creativas, y elaboración de piezas.

Con este proyecto se consigue que los alumnos saquen a relucir su lado profesional y creativo, a la vez que se enriquecen de una forma totalmente práctica. El profesor proporciona al inicio del curso las bases esenciales del 
proyecto, junto con un calendario a cumplir por parte de los alumnos en la entrega de las diferentes fases. A partir de entonces, queda en manos de los alumnos el organizarse y trabajar con la organización.

La primera toma de contacto entre el grupo de alumnos y la organización se lleva a cabo con la firma de un convenio de colaboración en el que se exponen las cláusulas a cumplir por ambas partes, donde el grupo de alumnos se compromete a:

- Contactar con la organización tan pronto como sea posible.

- Tener al menos dos reuniones presenciales, siempre que sea posible, o por cualquier otro procedimiento que se pacte entre las partes, con los responsables del proyecto en la ONG (una de presentación inicial del contrabriefing y otra de presentación de la campaña final elaborada).

- Elaborar la campaña publicitaria siguiendo la información establecida en el briefing y teniendo en cuenta las matizaciones posteriores de los representantes de la organización.

- Respetar los principios, la misión y la visión de la organización, así como sus códigos de conducta.

Los alumnos autorizan también la participación de las piezas en certámenes de publicidad social, tanto nacionales como internacionales.

Tras esto, la organización procede a la entrega de un briefing en el que se detallan los aspectos a trabajar como: el objetivo de la campaña, la estrategia de comunicación, los medios de comunicación en los que se va a difundir la campaña, el timing o las limitaciones. Los alumnos realizan un contrabriefing que debe ser aceptado por la organización para así proceder a la siguiente fase del proyecto.

Tras reunirse con la Organización, los alumnos deben presentar los informes de reunión, en los que se especifica los temas tratados en la misma, así como los asistentes. El proceso continúa con la presentación de ideas por parte de los alumnos a la Organización y, tras su aceptación, se lleva a cabo la ejecución de dichas ideas.

Durante los años que se ha realizado esta práctica, los estudiantes han prestado su colaboración a diferentes organizaciones tales como: 1) Anesvad, 2) Farmacéuticos Mundi, 3) Salud para todos, 4) Pacto mundial, 5) FAD, 6) Codespa, 7) Movimiento por la paz, 8) Adanter, 9) Al día, 10) Cáritas Getafe, 11) Greenpeace, 12) Setem, 13) Un solo mundo, 14) Asamblea cooperación por la paz, 15) Cruz roja, 16) Juntos para jugar, 17) Maison des enfants, 18) Funciona, 19) Vicente Ferrer, 20) Nelson Mandela, 21) Comercio justo web, 22) Acsur las segovias, 23) Acción contra el hambre, 24) Manos Unidas, 25) Fundación Tomillo, 26) Comercio justo, 27) Cáritas española, 28) Jóvenes y desarrollo, 29) Abenin, 30) Fundación San Ezequiel, 31) Cesal, 32) Asociación Miguel Fenollera, 33) Intermon, 34) ASZA, 35) Accem, 36) Cupif. 
Los alumnos trabajan también en difundir las prácticas de publicidad social en la página diseñada por ellos mismos en http://solidarydar.weebly.com/. Y con su participación en el Festival Universitario de Publicidad Social en Solidarydar.org que se celebra en la Universidad Rey Juan Carlos, http://solidarydar.weebly.com/publicidad-social.html. Asimismo, la publicidad solidaria se ha hecho un lugar entre las redes sociales más importantes, contando con perfiles tanto en Facebook, como Tuenti o Twitter e incluso dispone de un canal propio en la gran plataforma YouTube.

\section{Resultados}

A continuación se desarrollan las diferentes funciones que tiene la web de Solidarydar.org en cuanto a la arquitectura de la información, como a las funcionalidades del portal.

\section{Contenidos de la plataforma}

Se presenta a continuación el contenido de la web, ya que es la información que el alumno busca cuando entra al portal y es uno de los aspectos que le da valor a la plataforma Solidarydar.org:

- Solidarydar.org ¿quiénes somos?: en esta parte se plantea una introducción de la labor de Solidarydar. org y una presentación de nuestra función, añadiendo en qué consiste este proyecto y una descripción de quiénes somos y qué pueden encontrar en esta web.

- Investigaciones: el contenido de investigaciones tiene como fin mostrar las investigaciones, que se han hecho en este campo de investigación del tercer sector y la publicidad social. Es un punto de referencia y de consulta, tanto para el desarrollo de proyectos, como para informarse de las investigaciones en este sector.

- Campañas: la sección de las campañas es una de las más importantes, ya que ahí se encuentran todas las campañas que se han realizado. Además cuenta con un apartado en el que se desarrolla la historia de la organización, fundación, ONG o asociación. Es el espacio que se ofrece para cada una de las entidades que colaboran con Solidarydar.org. Ellas forman parte de nosotros y tienen un espacio particular en la web.

- Jornadas: en el apartado de jornadas donde se encuentran las diferentes jornadas y festivales que se han llevado a cabo cada año.

- Participa: este módulo está reservado para los participantes y colaboradores, esto es, para los comunicadores-alumnos y las entidades del tercer sector que quieran formar parte del proyecto. Los comunicadores pueden apuntarse directamente para participar en un proyecto, y las entidades del tercer sector tienen un espacio para contactar directamente con la plataforma. En este apartado se publican las diferentes ofertas de proyectos.

- Proyectos en ejecución: donde aparece el equipo de Solidarydar.org que está realizando el proyecto social con la ONG, asociación o fundación asignada.

- Blog Solidarydar.org: el blog es un complemento en el que se publican noticias de actualidad, curiosidades, acciones que desarrollan las diferentes entidades colaboradoras y las acciones sociales que se van desarrollando en el sector de la publicidad social. 


\section{Estructura de la plataforma}

La web se estructura de forma sencilla para que el usuario encuentre de una forma rápida lo que busca en ella. La web se divide en tres partes: cabecera, cuerpo de página y pie de página. A continuación se describen las partes de la plataforma con los elementos que la componen.

\section{Página de inicio}

En la cabecera se encuentran los iconos de las redes sociales de Solidarydar.org y más abajo está el menú de navegación. A continuación un slider que pasa las imágenes de las noticias relevantes o destacadas sobre Solidarydary.org.

Figura 1. Cabecera de Solidarydar.org

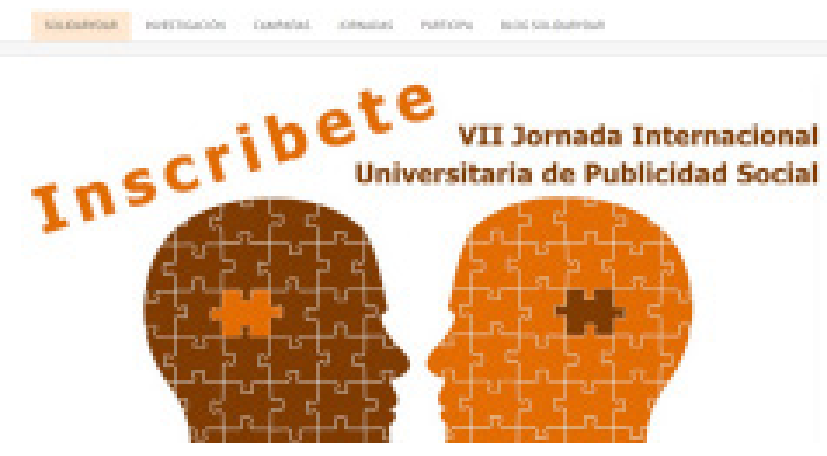

Fuente: Tomado de la web solidarydar.org. Arroyo, López y Gutiérrez (2015).

En el body, o cuerpo de página, encontramos las pastillas informativas que presentan la información con una pequeña descripción y una imagen relacionada.

Figura 2. Cuerpo de página, primera parte

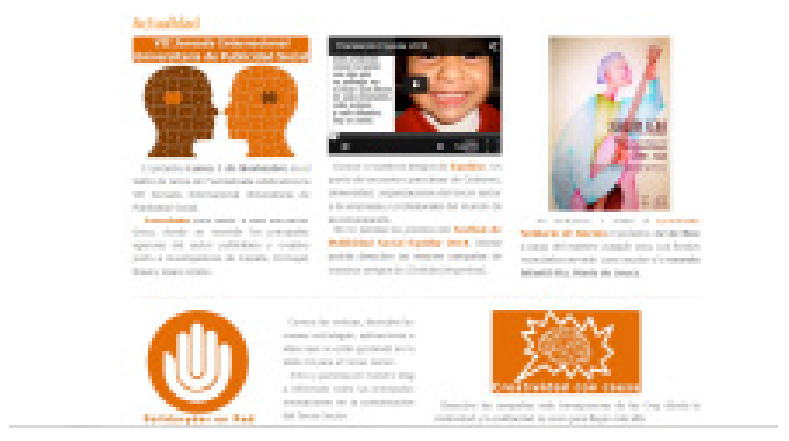

Fuente: Tomado de la web solidarydar.org. Arroyo, López y Gutiérrez (2015). 
Estas pastillas informativas desarrollan noticias de actualidad, como: comienzo de proyectos, acciones que se están realizando y publicación de las jornadas, entre otras. Luego encontramos los enlaces directos hacia los apartados de "Creatividad con Causa" y "Solidaridad en la Red". En la última parte del cuerpo de página se encuentran otras pastillas informativas con información sobre la plataforma de Solidarydar.org, que enlaza con las investigaciones, las jornadas, los participantes y las campañas que han realizado.

Figura 3. Cuerpo de página, segunda parte

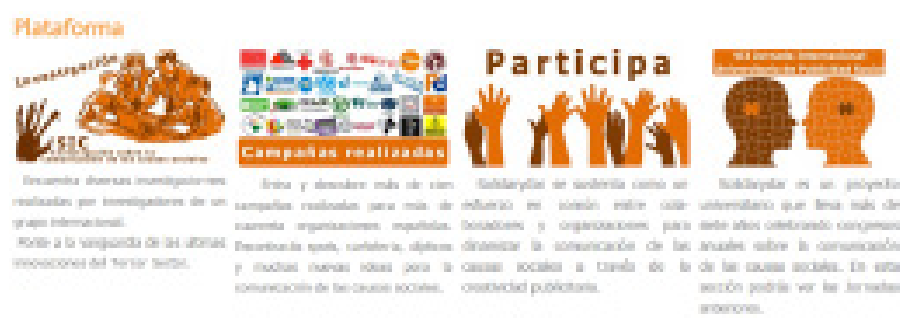

Fuente: Tomado de la web solidarydar.org. Arroyo, López y Gutiérrez (2015).

\section{Menú}

El menú se compone de las siguientes pestañas: 'Solidarydar.org', 'Investigación', 'Campañas', 'Jornadas', ‘Participa' y 'Blog Solidarydar.org'.

El menú se organiza según el tipo de interés. En primer lugar, por intereses relacionados con el proyecto y las investigaciones relacionadas con la publicidad social. En segundo lugar, por intereses que tienen que ver con las funciones y acciones que se han llevado a cabo. En tercer lugar, los intereses que tienen que ver con la interacción y la acción con Solidarydar.org, esta es, la llamada a la acción para participar. Por último, el blog como herramienta de interacción e intercambio de información.

\section{Secciones de la web}

- Solidarydar.org: esta sección se divide en dos partes; una en la que se presenta la plataforma introduciendo un quienes somos, y otra en la que puedes acceder a la presentación más específica del proyecto. 


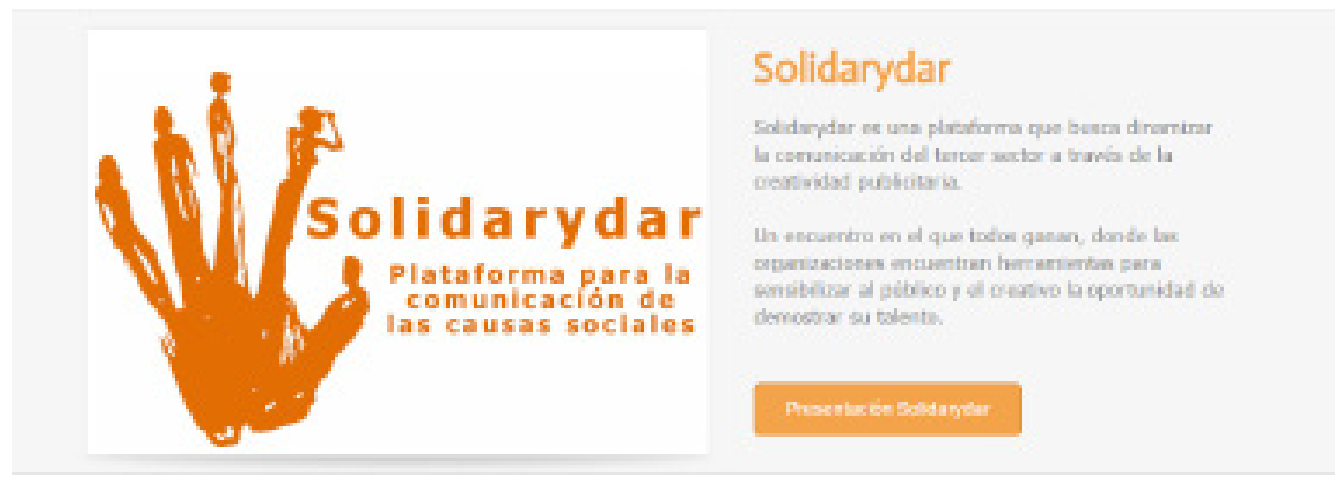

Fuente: Tomado de la web solidarydar.org. Arroyo, López y Gutiérrez (2015).

- Investigaciones: esta sección se compone de una parte informativa que describe la sección. A continuación se presentan los proyectos de forma gráfica, y con una pequeña descripción. A partir de ahí, se puede hacer clic en cualquiera de ellos para acceder a la investigación deseada. Tiene una estructura sencilla y visual.

Figura 5. Página de investigación

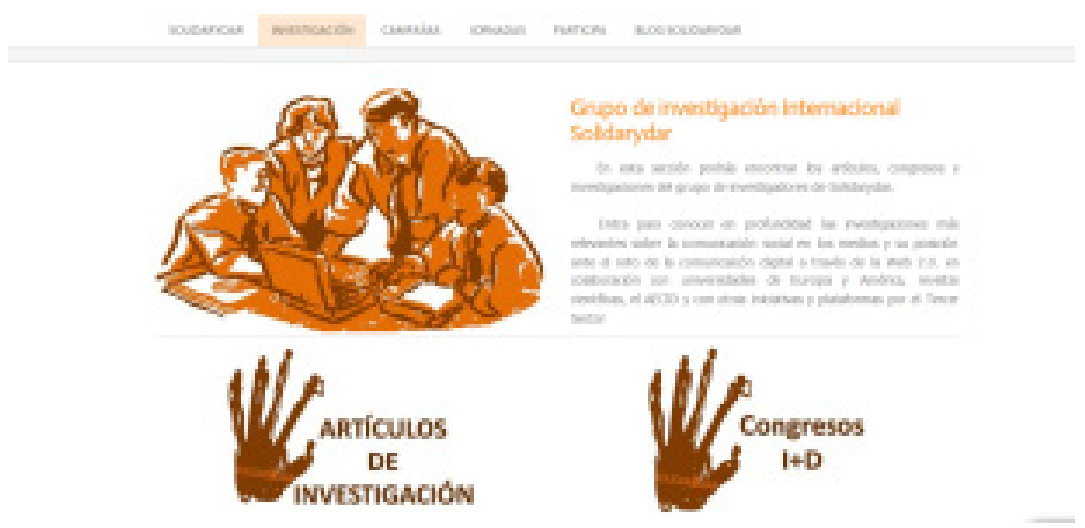

Fuente: Tomado de la web solidarydar.org. Arroyo, López y Gutiérrez (2015).

- Campañas: esta sección es una de las más importantes, puesto que es donde podemos encontrar todo el trabajo realizado por Solidarydar.org. Está organizado por entidades del tercer sector. Aparecen las ONG, las fundaciones, o las organizaciones organizadas por orden alfabético. Estas tienen un enlace a la página de cada organización. A continuación, se aprecian los logos de todas las entidades que han colaborado con Solidarydar.org, al igual que con el apartado anterior, estas también llevan a la sección correspondiente de la web en Solidarydar.org. 


\section{ENSAYOS}

Figura 6. Página de campañas (texto)

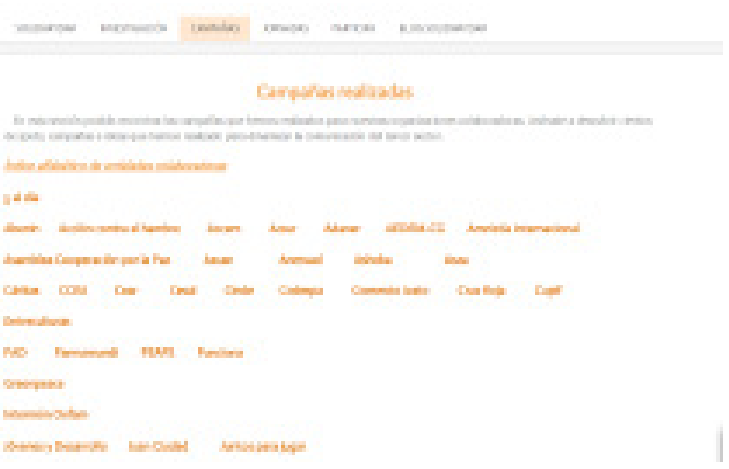

Fuente: Tomado de la web solidarydar.org. Arroyo, López y Gutiérrez (2015).

Figura 7. Página de campañas (imágenes)

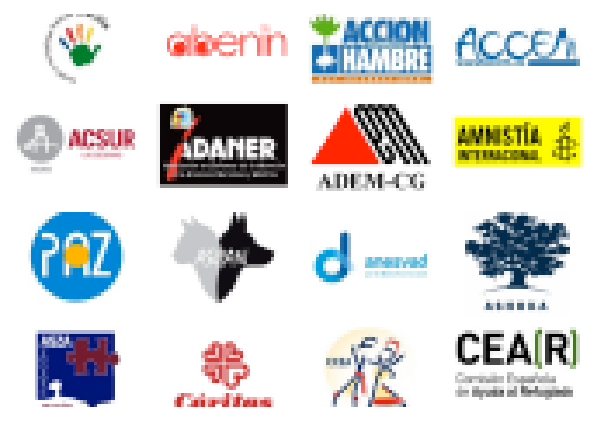

Fuente: Tomado de la web solidarydar.org. Arroyo, López y Gutiérrez (2015).

La disposición interna de cada sección de las ONG que han colaborado con Solidarydar.org varía dependiendo del material disponible y de las acciones que se han realizado. Sin embargo, lo habitual es contar con el logo y la descripción de la organización, así como las campañas realizadas, los documentos aportados por la organización, los resultados de esas campañas y las acciones realizadas por los participantes. 


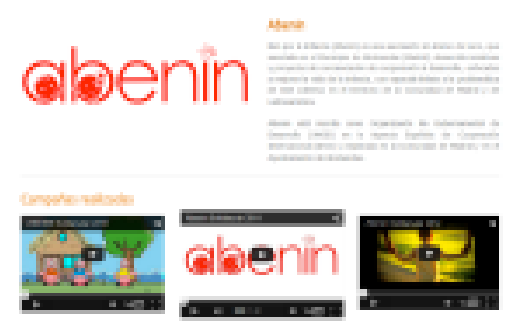

Fuente: Tomado de la web solidarydar.org. Arroyo, López y Gutiérrez (2015).

Figura 9. Página de ONG desarrollo de briefing

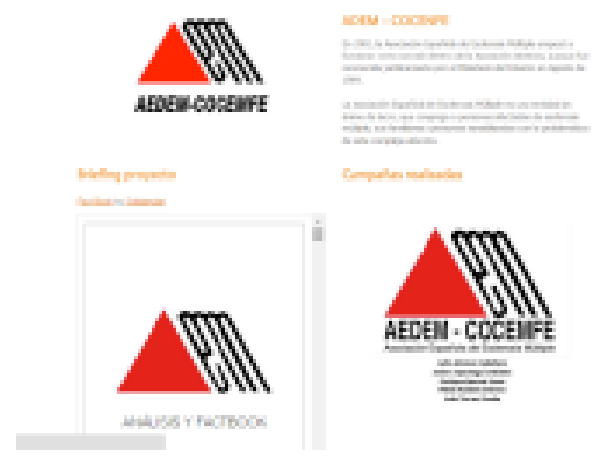

Fuente: Tomado de la web solidarydar.org. Arroyo, López y Gutiérrez (2015).

- Participa: esta sección es una de las primordiales, dado que es la que invita a realizar la acción y la sinergia entre las dos entidades. En esta sección es donde se solicita la participación de los comunicadores y las organizaciones en el proyecto. En la primera parte del cuerpo de página hay una imagen, luego hay una composición de botones que lleva directamente a los formularios para solicitar participar en el proyecto. También se encuentra una breve descripción de esta sección. En la segunda parte, encontramos dos secciones en las que se indican los proyectos que hay actualmente en marcha y los proyectos futuros. De manera que, tanto los comunicadores, como las organizaciones se hagan una idea, de lo que se está realizando actualmente en Solidarydar.org. 


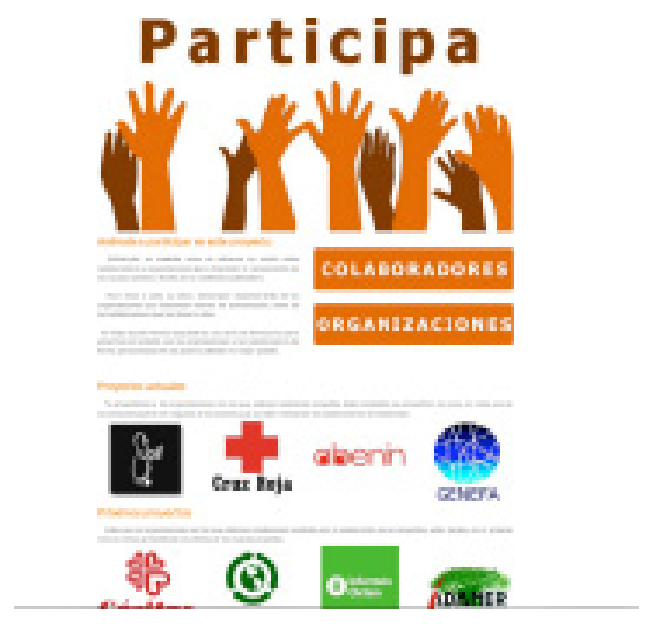

Fuente: Tomado de la web solidarydar.org. Arroyo, López y Gutiérrez (2015).

Figura 11. Sección de colabora dentro de participa

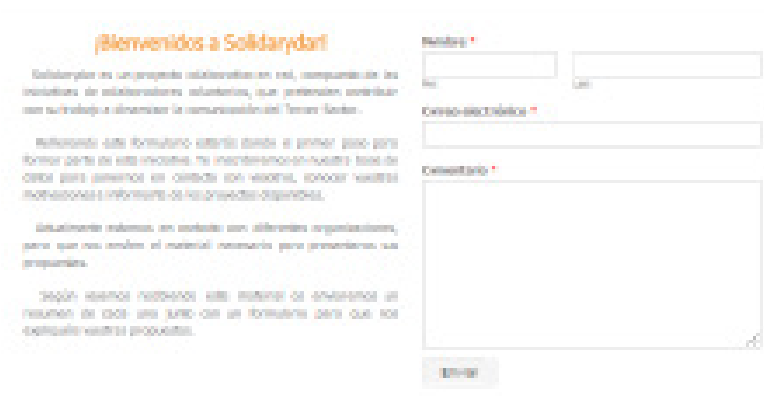

Fuente: Tomado de la web solidarydar.org. Arroyo, López y Gutiérrez (2015).

A continuación encontramos los botones de 'colaboradores' y 'organizaciones'. Ambas opciones tienen la misma presentación, hay una breve introducción de en qué consiste y su funcionamiento. Además de un formulario para solicitar participar en el proyecto.

Otra de las secciones es 'proyectos actuales'. Esta sección está compuesta por los logos de los proyectos que se están llevando a cabo. Haciendo clic en esos logos se va a la sección de los proyectos actuales organizados por organizaciones. Esta sección está compuesta por una presentación del equipo de participantes y una descripción del proyecto que están realizando con la organización. Esta es una sección clave para los participantes, porque aparece su nombre y parte de su vida profesional, también es una oportunidad para aparecer de forma profesional en una plataforma, la cual tiene acceso una comunidad de profesionales de la comunicación. Cabe destacar que, además de los estudiantes, algunos de los profesionales de la comunicación han estado también implicados en 
estos proyectos. Esta es una forma de reconocer la experiencia y profesionalidad de los comunicadores que participan en la plataforma.

Figura 12. Sección de Cupif, proyecto en marcha
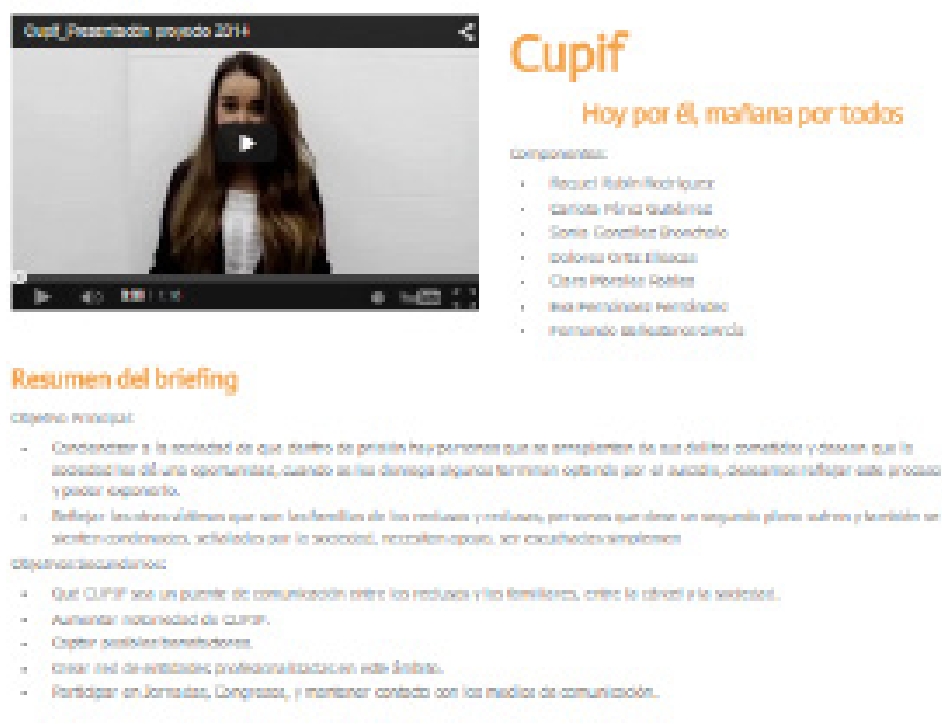

Fuente: Tomado de la web solidarydar.org. Arroyo, López y Gutiérrez (2015).

- Blog de Solidarydar.org: desde la web hay un enlace directo al blog de Solidarydar.org, este se encuentra en otro gestor de contenidos diferente al de la web. Principalmente, está formado por unas entradas con contenido relacionado con el tercer sector y la publicidad. Este está dividió por etiquetas y categorías de interés.

\section{Experiencia de usuario}

Se ha buscado que la experiencia del usuario sea lo primordial, razón por la cual se ha creado una imagen visual clara. También se ha trabajado para que el usuario obtenga lo que quiere dentro de la web en menos de tres clics. Se trata de un portal en la que el contenido es el principal protagonista. Todas las secciones tienen una descripción para mejorar el rendimiento y calidad de la web.

\section{Parte visual de la plataforma}

El diseño de la plataforma es sencillo, con una estructura de las secciones simple y clara. Los textos e imágenes se han diseñado con base en estilos propios de la web, teniendo en cuenta un diseño estético en cuanto colores, tipografías y tamaños. Los tonos que se usan son blancos, naranja, negros y grises. Los estilos básicos de la web son: el fondo blanco, los títulos naranja, el cuerpo de texto gris y negro. 


\section{Eficacia}

Esta práctica educativa innovadora ha aglutinado al día de hoy a 47 ONG colaboradoras, consiguiendo un buen número de seguidores en sus canales sociales de Twitter, Facebook e Instagram, entre otros. Además, destaca el número de visitas y de participantes en la web; siendo 5.703 visitas de tráfico cualificado (dato consultado desde Google Analytics en el periodo del 1 de enero de 2015 al 27 de junio de 2015). La tendencia se mantiene en la actualidad, tal y como se muestra en el gráfico 3.

\section{Gráfico 3. Estadísticas para solidarydar, correspondientes al periodo agosto y septiembre de 2015}

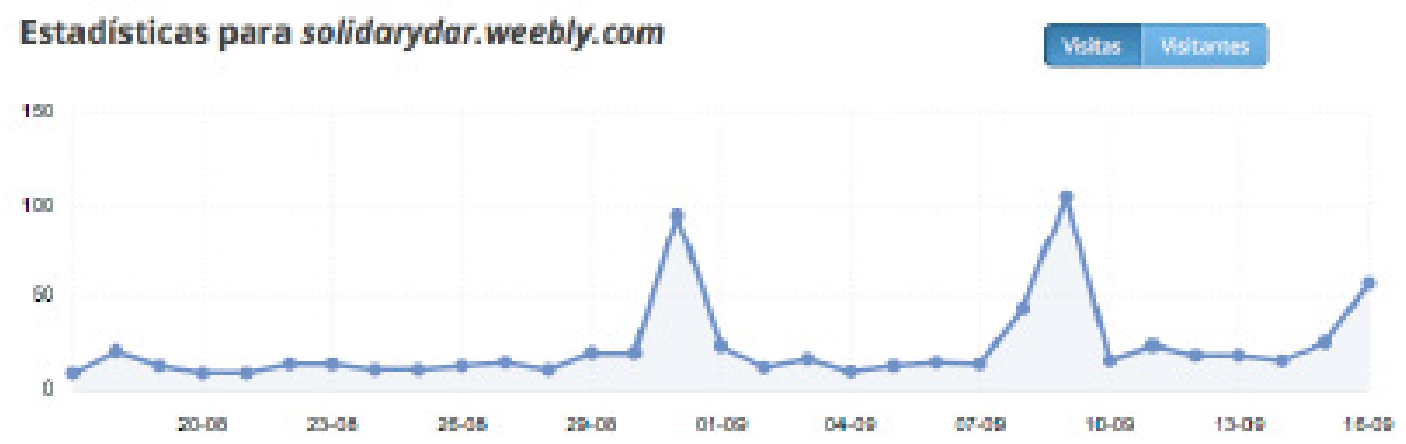

Fuente: Weebly.com (2015).

Las organizaciones del tercer sector han evaluado positivamente el procedimiento seguido por el proyecto para cumplir los objetivos propuestos. Así, por ejemplo, cuando se realizó una encuesta sobre el procedimiento seguido, se concluyó que estos fueron adecuados y no significaron un impedimento para la consecución de los objetivos, razón por la cual se ha mantenido el mismo procedimiento. A continuación se valoran los 6 aspectos que se citan en la tabla 1 con una escala de 1 a 7 ; siendo 1 el grado menor de consecución y 7 el grado máximo.

Tabla 1. Procedimiento de trabajo

\begin{tabular}{|l|c|c|}
\hline \multicolumn{1}{|c|}{ Procedimiento } & Puntuación & $\%$ \\
\hline Cumplimiento fechas & 5,27 & 75,28 \\
\hline Disponibilidad primer contacto & 5,58 & 79,71 \\
\hline Facilidad contacto & 5,36 & 76,57 \\
\hline Calidad contrabriefing & 4,94 & 70,57 \\
\hline Implicación & 5,18 & 74,00 \\
\hline Acceso material & 5,24 & 74,85 \\
\hline Posibilidad propuestas & 5,21 & 74,42 \\
\hline Media puntuaciones & 5,26 & 75,14 \\
\hline
\end{tabular}

Fuente: Arroyo (2015). 


\section{DISERTACIONES}

ENSAYOS

Anuario electrónico de estudios en Comunicación Social

ISSN: 1856-9536

Doi: dx.doi.org/10.12804/revistas.urosario.edu.co/disertaciones/a.4532

Volumen 10, Número 1/ Enero-junio 2017

Versión PDF para imprimir desde

http://revistas.urosario.edu.co/index.php/disertaciones

Igualmente, se ha evaluado en diferentes momentos el grado de "consecución y adecuación de las propuestas de los equipos creativos en relación con las demandas hechas por las distintas organizaciones", siendo siempre los resultados muy satisfactorios. A modo de ejemplo presentamos los resultados del periodo 2007-2011 con sus respectivas medias. Estos resultados son extrapolables con la situación actual.

Tabla 2. Eficacia de las campañas

\begin{tabular}{|c|c|c|c|c|c|c|c|}
\hline & 유 & 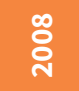 & 용 & 을 & 겅 & $\frac{\mathbb{2}}{\mathrm{g}}$ & $\%$ \\
\hline Calidad & 5,14 & 5,53 & 5,27 & 6,03 & 6,36 & 5,67 & 79,00 \\
\hline Aportaciones & 5,37 & 5,47 & 5,58 & 6,14 & 6,54 & 5,82 & 78,14 \\
\hline Intención de colaborar & 5,22 & 5,21 & 5,36 & 5,69 & 6,19 & 5,53 & 74,43 \\
\hline Adecuación & 5,02 & 5,71 & 4,94 & 5,86 & 6,38 & 5,58 & 81,57 \\
\hline Eficacia & 5,05 & 5,53 & 5,18 & 5,83 & 6,18 & 5,55 & 79,00 \\
\hline Creatividad & 5,28 & 5,79 & 5,24 & 6,06 & 6,96 & 5,87 & 82,71 \\
\hline Media puntuaciones & 5,22 & 5,54 & 5,21 & 6,23 & 6,72 & 5,78 & 79,14 \\
\hline
\end{tabular}

Fuente: Arroyo (2015).

Esta motivación e implicación de los estudiantes realizando campañas reales ha permitido a los estudiantes ganar premios en diferentes festivales. Así, en el Festival de Publicidad Social "Solidar\&dar", celebrado en Fuenlabrada en abril de 2010, la campaña de Cruz Roja ganó el primer premio, la de Adaner el segundo, la de Abenin el tercero, la de Cáritas Getafe el cuarto; la de la Coordinadora de Comercio Justo el quinto y la de Funciona el sexto. La campaña para Maison des Enfants ganó el primer premio del Publifestival Social 2010, celebrado en Málaga, y la de Accem el cuarto premio en la modalidad de Jóvenes Talentos (Arroyo, 2015, p. 206).

Las piezas elaboradas durante el curso 2010-2011 fueron presentadas a la V edición del Publifestival Social (Festival Internacional Profesional de la Publicidad Social) celebrado en Barcelona el día 6 de mayo de 2011 y las campañas elaboradas para las organizaciones Movimiento por la Paz y Greenpeace obtuvieron dos de los cuatro premios Jóvenes Talentos otorgados bajo esta modalidad.

La campaña "La pieza que nos falta eres tú" fue creada para el 18 de diciembre de 2012, Día Nacional de la Esclerosis Múltiple, por cinco estudiantes de Publicidad de la Universidad Rey Juan Carlos y fue elegida, de entre más de 500 proyectos presentados, con un premio en la categoría Joven Talento en la 3a edición del Festival Europeo de Publicidad Smile Festival que se celebró el 1 de marzo de 2013 en Caixa Forum.

El Lazo Múltiple solidario de la Esclerosis Múltiple tuvo un gran impacto por las mesas de información y cuestación de Madrid, medios de comunicación nacional (entre otros en el programa de Ana Rosa Quintana²) y en redes sociales con un alcance total que superó los dos millones y medio de personas. De nuevo un alumno del grupo de creatividad obtuvo en la elaboración del mensaje el premio Jóvenes Talentos en la $4^{\text {a }}$ edición del Smile Festival celebrado el 6 de marzo de 2015 en Caixa Forum.

2 Magazine matutino de gran éxito de audiencia en la televisión española, emitido por Telecinco. 
Durante el curso 2014-2015 se pusieron en marcha múltiples proyectos con alumnos de la Universidad Rey Juan Carlos. A continuación se expone, a modo de ejemplo, el proyecto con la ONG Cupif.

Los componentes del grupo se reunieron con la encargada de Cupif. Analizaron el briefing y a partir de ese momento el grupo empezó a trabajar en ello y creó una estrategia de comunicación on line, vía Twitter.

La acción consistía en una estrategia en redes sociales, en especial en Twitter. Esto es, hacerse una fotografía y subirla al perfil con una frase y un hashtag determinado. Actualmente, parte de este grupo sigue colaborando con Cupif y algunos de ellos van a realizar las prácticas de la Universidad en su organización.

Figura 13. Acción en Twitter

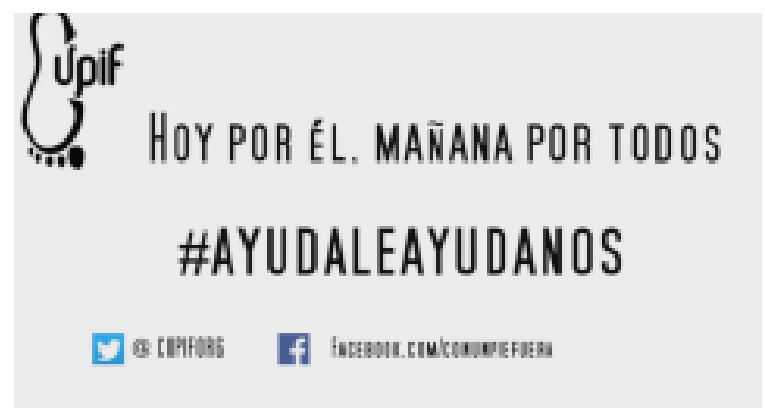

Fuente: Tomado de la web solidarydar.org Arroyo, López y Gutiérrez (2015).

\section{Llamada a la acción de la campaña}

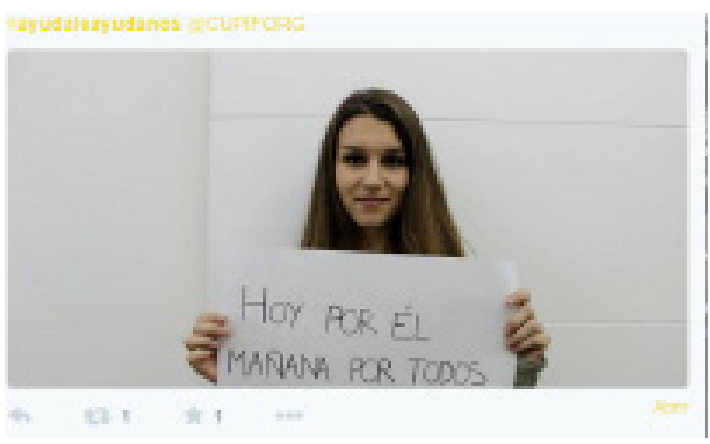

Fuente: Tomado de la web solidarydar.org Arroyo, López y Gutiérrez (2015).

La plataforma solidarydar.org y el Festival Universitario de Publicidad Social que se celebra cada año en la URJC empieza a ser un referente para los estudiantes del sector de comunicación. La celebración de la primera edición de las Jornadas Internacionales de Publicidad Social y el Festival de Publicidad Social Solidarydar.org realizado en 2007 en el Campus de Fuenlabrada tuvieron un gran impacto mediático con el cubrimiento de diarios como ABC, RNE, Cadena Ser, La Sexta, etc., cuyos resultados se pueden comprobar en la siguiente dirección web: http://www.elpublicista.com/frontend/elpublicista/noticia.php?id_noticia=2567\&id_seccion=20 


\section{DISERTACIONES}

ENSAYOS

Anuario electrónico de estudios en Comunicación Social

ISSN: 1856-9536

Doi: dx.doi.org/10.12804/revistas.urosario.edu.co/disertaciones/a.4532

Volumen 10, Número 1 / Enero-junio 2017

Versión PDF para imprimir desde

http://revistas.urosario.edu.co/index.php/disertaciones

Se continuó con la realización de la segunda, tercera, cuarta, quinta, sexta, séptima y octava ediciones de las Jornadas y el Festival que se celebraron en abril de 2008, 2009, 2010, noviembre de 2011, abril de 2013, 2014 y 2015 en el Salón de Actos del Edificio de Gestión del Campus de Fuenlabrada (Facultad de Ciencias de la Comunicación de la Universidad Rey Juan Carlos) y en Salón de Actos del campus de Vicálvaro. Su gran impacto mediático y social, y los resultados se pueden comprobar en:

- http://solidarydar.weebly.com/

- El País. Sociedad, 29 de agosto de 2008. "Si el refresco es solidario, lo compro". http://elpais.com/diario/2008/08/29/sociedad/1219960801_850215.html

- Canal plus. Programa Paso a Publicidad, 26 de noviembre de 2008 http://blogs.canalplus.es/paso_a_ publicidad/responsabilidad/

- Revista Época, 9 de mayo 2010, págs 59 y 60. "Causas que visten"

- El País. Sociedad, 24 de enero de 2011. "Cómo vender la solidaridad” http://sociedad.elpais.com/sociedad/2011/01/24/actualidad/1295823601_850215.html

Y con la publicación de las siguientes monografías:

- Publicidad Social, 2007. Servicio de Publicaciones de la URJC.

- La Comunicación de las ONG en Redes Sociales. Servicio Publicaciones de la URJC. Colección CD-Rom. ISBN 978-84-9982-324-9.

- Tendencias y eficacia de la Comunicación Audiovisual de las organizaciones sin ánimo de lucro en redes sociales. Dykinson, S.L. ISBN 978-84-9031-137-0.

- Reportaje fotográfico y Crónica de las VII Jornadas Internacionales de Publicidad social http://solidarydar. weebly.com/jornadas-vii.html

La plataforma de solidarydar.org, así como sus redes sociales, empiezan a tener usuarios habituales. Por ejemplo, el canal de YouTube de Solidarydar.org, donde se comparten las campañas realizadas, tiene actualmente 1.243 visualizaciones de los videos. Esto respalda la importancia de las plataformas sociales para dar a conocer las acciones emprendidas y crear comunidad. Como ya dijimos en otro lugar (Arroyo, 2012), "el vídeo on line está siendo utilizado como uno de los motores de la industria publicitaria on line gracias a su gran capacidad de segmentar a las audiencias y a su facilidad para medir el engagement con sus públicos" ( $\mathrm{p}$. 10). Por ello, destacamos la importancia de tener un canal de YouTube propio y activo con tantas visualizaciones de las campañas realizadas.

\section{Conclusiones y discusión}

La conclusión principal del proyecto de investigación es que se ha conseguido el principal objetivo de cooperar de forma continuada con el tercer sector. También se ha creado un punto de encuentro y sinergia entre ambos por medio de la plataforma de solidarydar.org.

Como dice Alvarado (2005) "hay una publicidad que, por encima de este interés social (planteamiento que también le subyace) es específica y doblemente social, ya que persigue fines vinculados con la mejora de los individuos y de las sociedades" (p. 265). Por lo cual podemos considerar a Solidarydar.org como una plataforma doblemente social y válida para la comunicación de las causas sociales. Gracias a solidarydar.org se está mejorando la comunicación de las entidades colaboradoras y la experiencia profesional de los alumnos que participan en ello. 


\section{DISERTACIONES}

ENSAYOS

Anuario electrónico de estudios en Comunicación Social

ISSN: $1856-9536$

Doi: dx.doi.org/10.12804/revistas.urosario.edu.co/disertaciones/a.4532

Volumen 10, Número 1 / Enero-junio 2017

Versión PDF para imprimir desde

http://revistas.urosario.edu.co/index.php/disertaciones

Cabe destacar que algunos alumnos que han participado en los proyectos, ahora forman parte de la plantilla de la ONG como colaboradores en el departamento de comunicación, lo que evidencia la eficacia de estas colaboraciones y cómo llevan al mercado laboral a nuestros comunicadores, siendo este último uno de los objetivos que nos planteábamos al principio.

Asimismo, esta investigación busca aportar al conocimiento sobre la realidad que se adviene sobre las organizaciones del tercer sector. Además de fomentar la comunicación de estas organizaciones en las redes sociales, las cuales, como podemos observar en una investigación realizada por Arroyo, Martín y Baladrón (2013), muestran algunas de las restricciones que frenan el empleo de estas redes, ya sea en el orden interno por falta de apoyo de la directiva de las organizaciones, al considerar que tienen menor impacto que los medios convencionales, o por otras restricciones como la pérdida aparente del control de la organización en el proceso de comunicación. Tendencias que observamos se están corrigiendo mediante el conocimiento, el diálogo y el consenso propiciado por los proyectos de elaboración propuestos.

A esta problemática se suman los recientes cambios en la administración y la legislación españolas, en concreto, la aprobación de la nueva Ley General de Subvenciones, de la que se desprende una normativa que atenaza a casi la totalidad de este sector en España. En concreto, medidas como la prevista en la redacción del artículo 19, en la que se expresa: "Cuando el importe de la subvención se determine en función del coste de la actividad o proyecto, la suma de subvenciones no podrá superar el $75 \%$ del coste de la actividad"; con lo que se constata que con la modificación de la ley, la financiación privada se hará de obligada necesidad. O la comprendida en el artículo 22, que prevé: "en ningún caso se consignarán subvenciones nominativas que restrinjan el acceso en igualdad de condiciones a otros potenciales solicitantes que puedan contribuir en similares circunstancias al fin público perseguido"; fomentando un marco de competencia al imponer la tutela de la administración en caso de concurrencia entre organizaciones con fines similares. Fomentando un entorno de colaboración unilateral en detrimento de fórmulas, que multilateralmente, busquen el consenso, la colaboración y el compromiso de todas las partes interesadas en una acción social concreta.

Sin embargo, el principal problema que observamos en nuestro proyecto ante la realidad que se avecina es la necesidad de rentabilizar y aprovechar al máximo los recursos de que disponemos. Esta necesidad reside esencialmente en la idea de impactar, de sobresalir, en el mercado del tercer sector a fin de aumentar la notoriedad, y con ello la labor social de estas organizaciones. Nuestra propuesta es conseguirlo mediante la originalidad y con el fomento de la creatividad, realizando campañas publicitarias eficaces, estructurando un mensaje que obedezca a un adecuado tratamiento de la dignidad y los valores de estas organizaciones. Se trata, en definitiva, de hacer buena publicidad a menor coste.

\section{Referencias}

1. Aguadero, F. (1993). Comunicación social integrada: un reto para la organización. Barcelona: Consejo Superior de Comunicación y Relaciones Públicas en España.

2. Alonso, C. (anual, 2004). La creatividad en la universidad: reflexiones para la profundización en el ámbito de la docencia. Creatividad y sociedad revista de la asociación para la creatividad, (6), 47-60.

3. Alvarado, M. (anual, 2005). La publicidad social: concepto, objeto y objetivos. Revista de estudios para el desarrollo social de la comunicación, (2), 265-284. 


\section{DISERTACIONES}

ENSAYOS

Anuario electrónico de estudios en Comunicación Social

ISSN: 1856-9536

Doi: dx.doi.org/10.12804/revistas.urosario.edu.co/disertaciones/a.4532

Volumen 10, Número 1 / Enero-junio 2017

Versión PDF para imprimir desde

http://revistas.urosario.edu.co/index.php/disertaciones

4. Angulo, G. (anual, 1998). El apoyo público a la cooperación al desarrollo. Revista española de desarrollo y cooperación, (2), 127-144.

5. Aranguren, L. (1998). Reinventar la solidaridad: voluntariado y educación. Madrid: Pensar, publicar, creer.

6. Arras, A., Torres, C. y García-Valcárcel, A. (junio, 2011). Competencias en tecnologías de información y comunicación (TIC) de los estudiantes universitarios. Revista latina de comunicación social, (66). Recuperado de http://www.revistalatinacs.org/11/art/927_Mexico/06_Arras.html

7. Arroyo, I. (octubre de 2011). Experiencia de elaboración de comunicación social persuasiva para ONG en el ámbito universitario para futuros profesionales de la publicidad. En García, A. (Director), Congreso educación mediática y competencia digital, Segovia, España

8. Arroyo, I. (octubre-diciembre, 2012). La comunicación eficiente del tercer sector. Telos cuadernos de comunicación e innovación, (93), 8-11.

9. Arroyo, I. (enero, 2015). Publicidad social eficaz desde la universidad: los aspectos experimentales. Revista de estudios de comunicación zer, 19(37), 191-211.

10. Arroyo, I., Martín, R. y Baladrón, A. (junio, 2013). La comunicación en redes sociales: percepciones y usos de las ONG españolas. Cuaderno info, (32), 77-88.

11. Cerdá, S. (2003). Las ONGD como agentes de la cooperación y la ayuda humanitaria. El caso español. Barcelona: Universidad Autónoma de Barcelona, Departamento de Comunicación Audiovisual y Publicidad.

12. Erro, J. (2002). Comunicación, desarrollo y ONGD. Bilbao: Hegoa.

13. Ferreras, E. (octubre-diciembre, 2011). Redes sociales y cambio social. El movimiento 15-M y su evolución en Twitter. Telos cuadernos de comunicación e innovación, (89), 61-74.

14. Grzybowski, C. (marzo, 2001). Las organizaciones no gubernamentales y la comunicación de masas: posibilidades de movilización. Comunicar, (16), 25-32.

15. Herranz de la Casa, J. y Cabezuelo, F. (julio, 2009). Comunicación y transparencia en las organizaciones sociales. Los blogs como generadores de transparencia en las ONG. Icono 14, 7(2), 172-194.

16. Jenkins, H. (2003). Transmedia Storytelling. Moving Characters from Books to Films to Video Vames Can Make Them Stronger and More Compelling. MIT Technology Review. Recuperado de https://www.technologyreview.com/s/401760/transmedia-storytelling/

17. Jenkins, H. (2008). Convergence Culture: la cultura de la convergencia de los medios de comunicación. Barcelona: Paidós.

18. Marí, V. (febrero, 2007). Contra la evaporación de la dimensión política de la comunicación. Movimientos sociales, ONG y usos de Internet. Revista de estudios de comunicación zer, (22), 453-471.

19. Ramil, X. Coord. (marzo, 2012). ParadigmáTIC@s Comunicación y cultura digital en las ONG de Desarrollo. Coordinadora de ONG para el Desarrollo-España: Madrid20. Ramírez del Río, A., Delgado, B. y Gómez, E. (2015). El tercer sector de acción social en 2015: Impacto de la crisis. Recuperado de http://www.plataformaong.org/ciudadaniaactiva/tercersector/estudio_completo_el_TSAS_en_2015_impacto_de_la_crisis.pdf

20. Scolari, C. (2008). Hipermediaciones: elementos para una teoría de la comunicación digital interactiva. Barcelona: Gedisa. 